\title{
Divergent structural brain abnormalities between different genetic subtypes of children with Prader-Willi syndrome
}

\author{
Akvile Lukoshe ${ }^{1,2^{*}}$, Tonya White ${ }^{3,4}$, Marcus N Schmidt ${ }^{3}$, Aad van der Lugt ${ }^{4}$ and Anita C Hokken-Koelega ${ }^{1,2}$
}

\begin{abstract}
Background: Prader-Willi syndrome (PWS) is a complex neurogenetic disorder with symptoms that indicate not only hypothalamic, but also a global, central nervous system (CNS) dysfunction. However, little is known about developmental differences in brain structure in children with PWS. Thus, our aim was to investigate global brain morphology in children with PWS, including the comparison between different genetic subtypes of PWS. In addition, we performed exploratory cortical and subcortical focal analyses.
\end{abstract}

Methods: High resolution structural magnetic resonance images were acquired in 20 children with genetically confirmed PWS (11 children carrying a deletion (DEL), 9 children with maternal uniparental disomy (mUPD)), and compared with 11 age- and gender-matched typically developing siblings as controls. Brain morphology measures were obtained using the FreeSurfer software suite.

Results: Both children with DEL and mUPD showed smaller brainstem volume, and a trend towards smaller cortical surface area and white matter volume. Children with mUPD had enlarged lateral ventricles and larger cortical cerebrospinal fluid (CSF) volume. Further, a trend towards increased cortical thickness was found in children with mUPD. Children with DEL had a smaller cerebellum, and smaller cortical and subcortical grey matter volumes. Focal analyses revealed smaller white matter volumes in left superior and bilateral inferior frontal gyri, right cingulate cortex, and bilateral precuneus areas associated with the default mode network (DMN) in children with mUPD.

Conclusions: Children with PWS show signs of impaired brain growth. Those with mUPD show signs of early brain atrophy. In contrast, children with DEL show signs of fundamentally arrested, although not deviant brain development and presented few signs of cortical atrophy. Our results of global brain measurements suggest divergent neurodevelopmental patterns in children with DEL and mUPD.

Keywords: Prader-Willi syndrome, Neurodevelopmental disorder, Chromosome 15q11-q13, Structural MRI

\section{Background}

Prader-Willi syndrome (PWS) is a rare and poorly understood neurodevelopmental disorder that affects 1 in 15,000 to 20,000 live births [1]. PWS is characterized by pre- and postnatal hypotonia, endocrine problems, hyperphagia, temper tantrums and repetitive behavior, skin picking, dysmorphic facial features, high pain

\footnotetext{
* Correspondence: a.lukose@kindengroei.nl

'Dutch Growth Research Foundation, Postbus 23068, Rotterdam 3001, KB, The Netherlands

${ }^{2}$ Department of Pediatrics, Erasmus Medical Center Rotterdam - Sophia Children's Hospital Rotterdam, Postbus 2060, Rotterdam 3000, CB, The Netherlands

Full list of author information is available at the end of the article
}

threshold, and developmental delays [2]. In addition, individuals with PWS carry a high risk of psychiatric illness, such as psychotic, obsessive-compulsive disorder (OCD), and autism spectrum disorders (ASD).

The underlying cause of PWS is the loss of function of paternally expressed genes on the long arm of chromosome 15q11-q13 due to a de novo deletion (DEL, approximately $70 \%$ of the cases [3]), maternal uniparental disomy (mUPD, 25\% of the cases [4]), and unbalanced translocation or imprinting center defects ( $<5 \%$ of cases [5]).

Lifetime prevalence of psychotic illness in individuals with PWS is reported to be up to $60 \%$ in individuals with mUPD and up to $20 \%$ in individuals with DEL [1],

\section{Biomed Central}


which is at least 18 times higher than that in the general population [6]. In addition, the mUPD patients are more likely to have a more severe course of the psychiatric illness, a higher frequency of relapse, and a poorer response to medication [7]. The underlying neurobiology that places them at-risk is yet unknown. Recently, copynumber variations (CNVs) at the 15q11.2 locus were found to be associated with schizophrenia and related psychosis [8], which suggests common genetic pathways between schizophrenia, psychotic disorders, and PWS.

In addition, individuals with PWS have a higher prevalence of ASD traits, such as impaired social functioning, rigidity, resistance to change, and repetitive, stereotypic behavior [9]. These autistic traits are more common in individuals with mUPD than in those with DEL (40\% versus $20 \%$, respectively). The autistic symptoms found in PWS are between 20 to 40 times higher than the $1 \%$ reported in the general population [10]. Chromosomal rearrangements of 15q11-13 locus have been found in patients with autism [11], suggesting that defective 15q11-13 genes might underlie the ASD traits in individuals with PWS. Further, recent findings indicate a plausible common neurodevelopmental pathway of autism, schizophrenia, and bipolar disorder, as family history of schizophrenia and bipolar disorder increased risk of autism in other family members [12], and several CNVs in genome-wide association studies (GWASs) were associated with developing either of these disorders [13].

Key symptoms indicate that the central nervous system (CNS) is adversely affected in PWS. To date, only two quantitative structural magnetic resonance imaging (MRI) studies have been performed in adults with PWS, which reported smaller grey matter volumes in the frontal, temporal, and parietal [14,15] lobes, and smaller white matter volumes in the frontal and temporal cortices, brainstem, and cerebellum [15]. An MRI qualitative study reported enlarged ventricles, decreased parietooccipital lobar volume, and sylvian fissure abnormalities in adults with PWS [16]. However, no quantitative structural or functional MRI studies have been performed in children with PWS, and there are no studies evaluating differences between children with DEL and mUPD. Since the DEL and mUPD subtypes of PWS differ in their risk of developing severe psychiatric disorders, a better understanding of the neurobiology of these subtypes will shed light on at-risk states.

In the current study, we utilized high resolution MRI to investigate the brain morphology in children with two subtypes of PWS (DEL and mUPD) in order to gain insights into the brain structure of young children with PWS as compared with their healthy siblings. We hypothesized that children with PWS, when compared with healthy siblings, will show global deficits that will be reminiscent of those reported in the adults with
PWS. Specifically, we expected smaller overall grey and white matter volume and larger lateral ventricular volume in children with PWS when compared with healthy controls. Since clinical data show that children with mUPD have greater social and cognitive deficits than children with DEL, we expected that the brain differences would be more pronounced in children with mUPD than in those with DEL. Furthermore, since children with MUPD show an increased risk of psychiatric disorders over children with DEL, we were also interested in brain differences which may indicate an increased risk of developing a severe psychiatric disorder.

\section{Methods}

The study population consisted of 25 children with PWS who participated in the Dutch PWS Cohort Study [17]. Patients fulfilled the following criteria: 1) genetically confirmed PWS subtype; 2) age 6 to 18 years old; and 3) no neurological or psychiatric history.

Eleven age- and gender-matched, typically developing siblings were included as a control group fulfilling the following inclusion criteria: 1) age 6 to 18 years old; and 2) no neurological or psychiatric history.

This study was approved by the Medical Ethical Committee of the Erasmus Medical Center Rotterdam, Rotterdam, The Netherlands. Written informed consent was obtained in all cases from the caregivers and children older than 12 years, and assent of children younger than 12 years.

\section{Intelligence assessment}

To assess intelligence of children, a short form of four subtests (vocabulary, similarities (verbal IQ subtests), block design, and picture arrangement (performance IQ subtests)) of the Wechsler Intelligence Scale for Children-Revised (WISC-R), Dutch version, was used [18]. Total IQ score was calculated according to an equation based on the Dutch outpatient population reference (total IQ $=45.3+2.91 \times$ vocabulary standard score $+2.50 \times$ block design standard score), as has been used in other studies [19].

\section{Procedure}

Prior to the MRI scan, all children were introduced to a mock scanner and all successfully completed the mock scanner protocol [20]. One of the caregivers opted to stay in the room with the MRI scanner, to remain close to their child.

\section{MRI acquisition}

Imaging was performed on a 3T GE 750 Discovery MRI scanner (General Electric, Milwaukee, WI, USA), using a dedicated 8-channel head coil. Following 3-plane localizing and coil intensity calibration scans, a high resolution 
T1-weighted inversion recovery fast spoiled gradient recalled (IR FSPGR) sequence was obtained with the following parameters: $\mathrm{TR}=10.3 \mathrm{~ms}, \mathrm{TE}=4.2 \mathrm{~ms}$, $\mathrm{TI}=350 \mathrm{~ms}, \mathrm{NEX}=1$, flip angle $=16^{\circ}$, readout bandwidth $=20.8 \mathrm{kHz}$, matrix $256 \times 256$, imaging acceleration factor of 2 , and an isotropic resolution of $0.9 \times$ $0.9 \times 0.9 \mathrm{~mm}^{3}$ (duration: 5 minutes 40 seconds). All MRI images were reviewed by a qualified radiologist (AvdL) within 2 weeks after the MRI acquisition. No gross brain abnormalities were identified.

\section{Data preprocessing and segmentation}

Five children with PWS were excluded from the MRI analysis due to motion artifacts, and failure of proper pial and white surface reconstruction by FreeSurfer (Athinoula A Martinos Center for Biomedical Imaging, Massachusetts General Hospital, Boston, MA, USA; http://surfer.nmr.mgh.harvard.edu), leaving 20 eligible patients for analysis (11 children with DEL, 9 children with mUPD).

Cortical reconstruction and volumetric segmentation was performed with the FreeSurfer 5.3 image analysis suite. The technical details of these procedures are described elsewhere [21-23]. Briefly, the processing included removal of non-brain tissue [22,24], automated Talairach transformation, segmentation of the subcortical white matter and deep grey matter volume structures [23,24], intensity normalization [25], and automated topology correction [26]. Parcellation of the cerebral cortex into units was performed based on gyral and sulcal structure [27]. Cortical thickness was calculated as the closest distance from the grey/white boundary to the grey/cerebrospinal fluid (CSF) boundary at each vertex on the tessellated surface [28]. Procedures for the measurement of cortical thickness have been validated against histological analysis [29]. FreeSurfer morphometric procedures have been demonstrated to show good test-retest reliability across scanner manufacturers and across field strengths [30]. All FreeSurfer outputs were manually reviewed by an author blinded to the patient data (AL), and manual edits were performed where needed to improve the white and pial surface reconstruction.

\section{Statistical analysis}

Results of cerebral cortex parcellation, based on gyral and sulcal structure, were exported to SPSS (version 20, IBM Corporation, Armonk, NY, USA) for appropriate statistical analyses. Nonparametric Kruskal-Wallis tests were performed for both global brain morphology measures and exploratory subcortical grey and white matter volumes. Pairwise comparisons were performed for significant main effects by conducting nonparametric Mann-Whitney tests. Bonferroni correction was applied $\left(P_{\text {corr }}=P \times 3\right)$ for group comparisons and we report adjusted $P_{\text {corr }}$ values unless indicated otherwise. The critical $P_{\text {corr }}$ value was set at 0.05 .

For global brain measurements, the BenjaminiHochberg false discovery rate (FDR) correction of $0.05 \%$ was applied to correct for multiple testing. Both uncorrected and FDR-corrected $P$ values are reported. No correction was performed for subcortical and cortical analyses as they were of exploratory nature.

For exploratory analyses, volume measures were corrected for total intracranial volume (TIV) by dividing each value by the individual's TIV value, which resulted in values between 0 and 1 , reflecting relative size of the particular structure in relation to the TIV. TIV was calculated as the sum of total cerebral grey and white matter volumes, lateral, third and fourth ventricles, choroid plexus, vessels, cerebellar grey and white matter, and surface CSF.

\section{Results}

Clinical data are presented in Table 1. No significant differences were found in age, handedness, and gender distribution among groups, and no differences in IQ scores and age at start of growth hormone $(\mathrm{GH})$ treatment. Only two children in the mUPD group were diagnosed with ASD. None of the children had a history of treatment with psychotropic medication.

\section{Global brain measures}

The results of global measures are presented in Table 2.

\section{DEL versus healthy controls}

Children with DEL had a significantly smaller TIV $\left(P_{\text {corr }}\right.$ $<0.01)$ when compared with healthy controls. They also had a significantly smaller total grey matter volume $\left(P_{\text {corr }}<0.01\right)$, both cortical $\left(P_{\text {corr }}<0.05\right)$ and subcortical $\left(P_{\text {corr }}<0.01\right)$, total white matter volume $(P=0.02$, not significant after Bonferroni correction), brainstem $\left(P_{\text {corr }}\right.$ $<0.01$ ), and cerebellum $\left(P_{\text {corr }}<0.01\right)$ (Table 2$)$. No differences were found in corpus callosum volume, lateral, third and fourth ventricles, and surface CSF compared with healthy controls.

After correction for TIV, the ratios of grey and white matter volume, brainstem, cerebellum, and lateral, third, and fourth ventricles to TIV were not significant between children with DEL and controls, which suggests that although overall smaller, the brain had developed proportionally (Table 3 ). However, the corpus callosum volume, corrected for TIV, was relatively larger $\left(P_{\text {corr }}<0.05\right)$.

\section{mUPD versus healthy controls}

No difference was found in TIV between children with mUPD and healthy controls. They also had normal total grey matter (cortical and subcortical) volumes compared with healthy controls. Total white matter volume was 
Table 1 Demographic data of the participants

\begin{tabular}{|c|c|c|c|c|}
\hline & \multicolumn{2}{|c|}{ PWS } & \multirow[t]{2}{*}{ Control } & \multirow[t]{2}{*}{$P$ value } \\
\hline & DEL & mUPD & & \\
\hline Age (years) & $12.3(3.2)$ & $10.6(2.5)$ & $11.7(2.7)$ & 0.40 \\
\hline Age range (years) & 6.7 to 17.0 & 6.8 to 13.1 & 7.1 to 15.8 & \\
\hline Head circumference SDS & $-0.37(0.84)$ & $0.8(1.2)$ & $\mathrm{n} / \mathrm{a}$ & $0.11^{\mathrm{a}}$ \\
\hline Sample size (n) & 11 & 9 & 11 & 0.26 \\
\hline Male & 5 & 4 & 8 & 0.60 \\
\hline Female & 6 & 5 & 3 & 0.50 \\
\hline Handedness (n) & & & & 0.25 \\
\hline Left & 1 & 6 & 1 & \\
\hline Right & 10 & 1 & 10 & \\
\hline Ambidextrous & 0 & 2 & 0 & \\
\hline $\begin{array}{l}\text { Age at start of GH } \\
\text { treatment (years) }\end{array}$ & $5.8(3.0)$ & $4.4(1.8)$ & & 0.37 \\
\hline Total IQ score & $69.5(16.0)$ & $67.2(14.5)$ & & 0.82 \\
\hline Verbal IQ & $4.7(3.4)$ & $4.0(2.6)$ & & 0.66 \\
\hline Performance IQ & $4.7(2.8)$ & $4.2(2.9)$ & & 0.60 \\
\hline Psychiatric history & 0 & $2^{\mathrm{b}}$ & & \\
\hline $\begin{array}{l}\text { Use of psychotropic } \\
\text { medication }\end{array}$ & 0 & 0 & & \\
\hline
\end{tabular}

Data expressed as mean (SD) or number. No significant differences were found in either age or gender distribution across groups. ${ }^{2}$ Values of DEL and mUPD were compared to 0 SDS; ${ }^{b}$ two children diagnosed with ASD prior to MRI scan. DEL, deletion; GH, growth hormone; mUPD, maternal uniparental disomy; n/a, not applicable; PWS, Prader-Willi syndrome; SD, standard deviation; SDS, standard deviation score.

smaller $(P=0.03$, not significant after Bonferroni correction). Children with mUPD also had a smaller brainstem volume $\left(P_{\text {corr }}<0.05\right)$, enlarged lateral ventricles $\left(P_{\text {corr }}\right.$ $<0.01)$, and larger surface CSF $\left(P_{\text {corr }}<0.05\right)$ (see also Figure 1). No differences were found in cerebellum and corpus callosum volume or third and fourth ventricles (Table 2).

After correction for TIV, a significantly disproportionate increase in the volume of lateral ventricles $\left(P_{\text {corr }}<0.01\right)$ and surface CSF $\left(P_{\text {corr }}<0.05\right)$ was found (Additional file 1: Table S1).

\section{DEL versus MUPD}

Children with DEL had a smaller total grey matter volume $(P=0.04$, not significant after Bonferroni correction), subcortical grey matter volume $\left(P_{\text {corr }}<0.05\right)$, and cerebellum $\left(P_{\text {corr }}<0.05\right)$ compared with children with mUPD (Table 2).

After correction for TIV, children with DEL had significantly larger corpus callosum than children with mUPD $\left(P_{\text {corr }}<0.05\right)$ (Additional file 1: Table S1).

\section{Exploratory focal measures \\ Cortical grey matter volumes}

Cortical grey matter volumes, corrected for TIV, are presented in Table 3 and Figure 1. We report only significant results. The non-significant findings can be provided upon request.

\section{DEL versus healthy controls}

Children with DEL had a significantly larger volume of right superior parietal lobe $\left(P_{\text {corr }}<0.01\right)$, larger volume of banks of left superior temporal sulcus $(P=0.02$, not significant after Bonferroni correction), and smaller volume of right parahippocampal gyrus $(P=0.037$, not significant after Bonferroni correction) compared with healthy controls.

\section{mUPD versus healthy controls}

Children with mUPD had smaller grey matter volumes in right parahippocampal gyrus $\left(P_{\text {corr }}<0.05\right)$ and left entorhinal $(P=0.04$, not significant after Bonferroni correction) compared with healthy controls. Further, children with mUPD had significantly larger right superior parietal lobe $\left(P_{\text {corr }}<0.01\right)$ and banks of right superior sulcus $\left(P_{\text {corr }}<0.05\right)$.

\section{DEL versus MUPD}

Children with mUPD had smaller cortical grey matter volumes in right lingual gyrus $\left(P_{\text {corr }}<0.05\right)$, left entorhinal $\left(P_{\text {corr }}<0.05\right)$, and banks of left and right superior temporal sulcus $(P=0.047$ and $P=0.03$, respectively, not significant after Bonferroni correction) when compared to children with DEL, but not from those in healthy controls.

\section{Cortical white matter volumes}

Cortical white matter volumes, corrected for TIV, are presented in Table 4 and Figure 2. We report only significant findings. The non-significant findings can be provided upon request.

\section{DEL versus healthy controls}

Children with DEL had smaller white matter volume of left pars orbitalis $(P=0.03$, not significant after Bonferroni correction) compared with healthy controls. No other differences were found.

\section{mUPD versus healthy controls}

Children with mUPD had smaller white matter volumes in left superior frontal gyrus $\left(P_{\text {corr }}<0.01\right)$, left pars orbitalis $(P=0.02$, not significant after Bonferroni correction), right pars triangularis $\left(P_{\text {corr }}<0.05\right)$, right pars orbitalis $\left(P_{\text {corr }}<0.01\right)$, and right posterior cingulate $\left(P_{\text {corr }}\right.$ $<0.05)$ compared with healthy controls. 
Table 2 Global brain volumes in children with PWS and healthy controls

\begin{tabular}{|c|c|c|c|c|c|c|c|c|c|c|}
\hline & \multicolumn{4}{|c|}{ PWS } & \multicolumn{2}{|c|}{ Control } & \multirow{3}{*}{$\begin{array}{l}P \text { value } \\
\text { Between groups } \\
\text { (FDR-corrected) }\end{array}$} & \multirow{3}{*}{$\begin{array}{l}P_{\text {corr }} \text { value } \\
\text { DEL } \\
\text { versus } \\
\text { control }\end{array}$} & \multirow{3}{*}{$\begin{array}{l}P_{\text {corr value }} \\
\text { mUPD } \\
\text { versus } \\
\text { control }\end{array}$} & \multirow{3}{*}{$\begin{array}{l}P_{\text {corr value }} \\
\text { mUPD } \\
\text { versus } \\
\text { DEL }\end{array}$} \\
\hline & \multicolumn{2}{|c|}{ DEL } & \multicolumn{2}{|c|}{ mUPD } & \multirow[b]{2}{*}{ Mean } & \multirow[b]{2}{*}{ SD } & & & & \\
\hline & Mean & SD & Mean & SD & & & & & & \\
\hline TIV $\left(\mathrm{mm}^{3}\right)$ & $1,234,546$ & 107,087 & 133,1869 & 128,966 & $1,410,393$ & 98,231 & $0.007(0.02)$ & 0.005 & ns & ns \\
\hline Total GM $\left(\mathrm{mm}^{3}\right)$ & 684,884 & 59,560 & 754,819 & 74,391 & 788,263 & 67,474 & $0.008(0.02)$ & 0.007 & ns & 0.118 \\
\hline Cortical GM $\left(\mathrm{mm}^{3}\right)$ & 511,270 & 53,409 & 563,276 & 65,484 & 588,374 & 60,604 & $0.026(0.047)$ & 0.026 & ns & ns \\
\hline Subcortical GM $\left(\mathrm{mm}^{3}\right)$ & 173,615 & 12,739 & 191,543 & 11,495 & 199,890 & 2,525 & $<0.001(0.001)$ & $<0.0001$ & ns & 0.036 \\
\hline Total WM $\left(\mathrm{mm}^{3}\right)$ & 408,399 & 45,050 & 413,740 & 60,537 & 462,809 & 38,073 & $0.034(0.053)$ & 0.061 & 0.098 & ns \\
\hline Total CC $\left(\mathrm{mm}^{3}\right)$ & 3,053 & 345 & 2,784 & 533 & 3,010 & 342 & ns (ns) & ns & ns & ns \\
\hline Brainstem $\left(\mathrm{mm}^{3}\right)$ & 16,207 & 1,378 & 17,384 & 1,511 & 20,493 & 1,858 & $<0.001(0.001)$ & $<0.0001$ & 0.016 & ns \\
\hline \multicolumn{11}{|l|}{ Ventricles $\left(\mathrm{mm}^{3}\right)$} \\
\hline Lateral $\left(\mathrm{mm}^{3}\right)$ & 14,318 & 11,606 & 20,598 & 8,781 & 9,244 & 610 & $0.001(0.004)$ & ns & 0.006 & ns \\
\hline Third $\left(\mathrm{mm}^{3}\right)$ & 932 & 433 & 1,091 & 275 & 868 & 190 & ns (ns) & ns & ns & ns \\
\hline Fourth $\left(\mathrm{mm}^{3}\right)$ & 1,986 & 495 & 1,952 & 394 & 1,853 & 455 & ns (ns) & ns & ns & ns \\
\hline Cerebellum $\left(\mathrm{mm}^{3}\right)$ & 124,737 & 11,456 & 141,378 & 9,644 & 146,092 & 11,022 & $0.001(0.004)$ & 0.001 & ns & 0.042 \\
\hline Surface CSF $\left(\mathrm{mm}^{3}\right)$ & 1,199 & 395 & 1,469 & 253 & 1,077 & 255 & $0.027(0.047)$ & ns & 0.029 & 0.133 \\
\hline Mean cortical thickness (mm) & 2.77 & 0.104 & 2.89 & 0.185 & 2.8 & 0.106 & $0.066(0.08)$ & & & \\
\hline Mean pial cortical area $\left(\mathrm{mm}^{2}\right)$ & 221,117 & 22,519 & 232,867 & 20,785 & 249,491 & 23,373 & $0.05(0.07)$ & & & \\
\hline
\end{tabular}

Both uncorrected and FDR-corrected $P$ values are reported. $P$ corr values that did not survive the Bonferroni correction are included. CC, corpus callosum; CSF, cerebrospinal fluid; $D E L$, deletion; FDR, false discovery rate; GM, grey matter; $m U P D$, maternal uniparental disomy; ns, not significant; PWS, Prader-Willi syndrome; $S D$, standard deviation; TIV, total intracranial volume; WM, white matter.

\section{DEL versus mUPD}

Children with mUPD had smaller white matter volumes in bilateral precuneus $\left(P_{\text {corr }}<0.05\right)$ and right caudal anterior cingulate cortex $\left(P_{\text {corr }}<0.01\right)$ when compared to children with DEL. Further, these children had smaller right pars orbitalis $(P=0.042$, not significant after Bonferroni correction), left superior frontal gyrus $\left(P_{\text {corr }}<0.05\right)$, and right posterior cingulate cortex $\left(P_{\text {corr }}<0.01\right)$ compared with children with DEL and healthy controls.

Table 3 Focal cortical grey matter volumes in children with PWS and healthy controls

\begin{tabular}{|c|c|c|c|c|c|c|c|c|c|c|}
\hline & \multicolumn{4}{|c|}{ PWS } & \multicolumn{2}{|c|}{ Control } & \multirow{3}{*}{$\begin{array}{c}P \text { value } \\
\text { between } \\
\text { groups }\end{array}$} & \multirow{3}{*}{$\begin{array}{l}P_{\text {corr value } D E L} \\
\text { versus control }\end{array}$} & \multirow{3}{*}{$\begin{array}{l}P_{\text {corr }} \text { value mUPD } \\
\text { versus control }\end{array}$} & \multirow{3}{*}{$\begin{array}{c}P_{\text {corr value }} \\
\text { mUPD versus } \\
\text { DEL }\end{array}$} \\
\hline & \multicolumn{2}{|c|}{ DEL } & \multicolumn{2}{|c|}{ mUPD } & \multirow[b]{2}{*}{ Mean } & \multirow[b]{2}{*}{ SD } & & & & \\
\hline & Mean & SD & Mean & SD & & & & & & \\
\hline Left entorhinal & 0.00153 & 0.00025 & 0.00123 & 0.00039 & 0.00148 & 0.00033 & 0.028 & ns & 0.127 & 0.031 \\
\hline $\begin{array}{l}\text { Left banks } \\
\text { of STS }\end{array}$ & 0.00237 & 0.00027 & 0.00217 & 0.00053 & 0.00204 & 0.00032 & 0.041 & 0.06 & ns & 0.142 \\
\hline $\begin{array}{l}\text { Right superior } \\
\text { parietal }\end{array}$ & 0.01359 & 0.00127 & 0.01363 & 0.00142 & 0.01163 & 0.00099 & 0.002 & 0.006 & 0.006 & ns \\
\hline Right lingual & 0.00621 & 0.00072 & 0.00532 & 0.00087 & 0.00584 & 0.00059 & 0.032 & ns & ns & 0.027 \\
\hline $\begin{array}{l}\text { Right } \\
\text { parahippocampal }\end{array}$ & 0.00162 & 0.00021 & 0.00154 & 0.0003 & 0.00194 & 0.00036 & 0.014 & 0.11 & 0.016 & ns \\
\hline $\begin{array}{l}\text { Right banks of } \\
\text { STS }\end{array}$ & 0.00201 & 0.00026 & 0.00237 & 0.00033 & 0.00202 & 0.00045 & 0.032 & ns & 0.045 & 0.091 \\
\hline
\end{tabular}

All measures presented in table are corrected for TIV. $P_{\text {corr }}$ values that did not survive the Bonferroni correction are included. DEL, deletion; mUPD, maternal uniparental disomy; ns, not significant; PWS, Prader-Willi syndrome; SD, standard deviation; STS, superior temporal sulcus; TIV, total intracranial volume. 


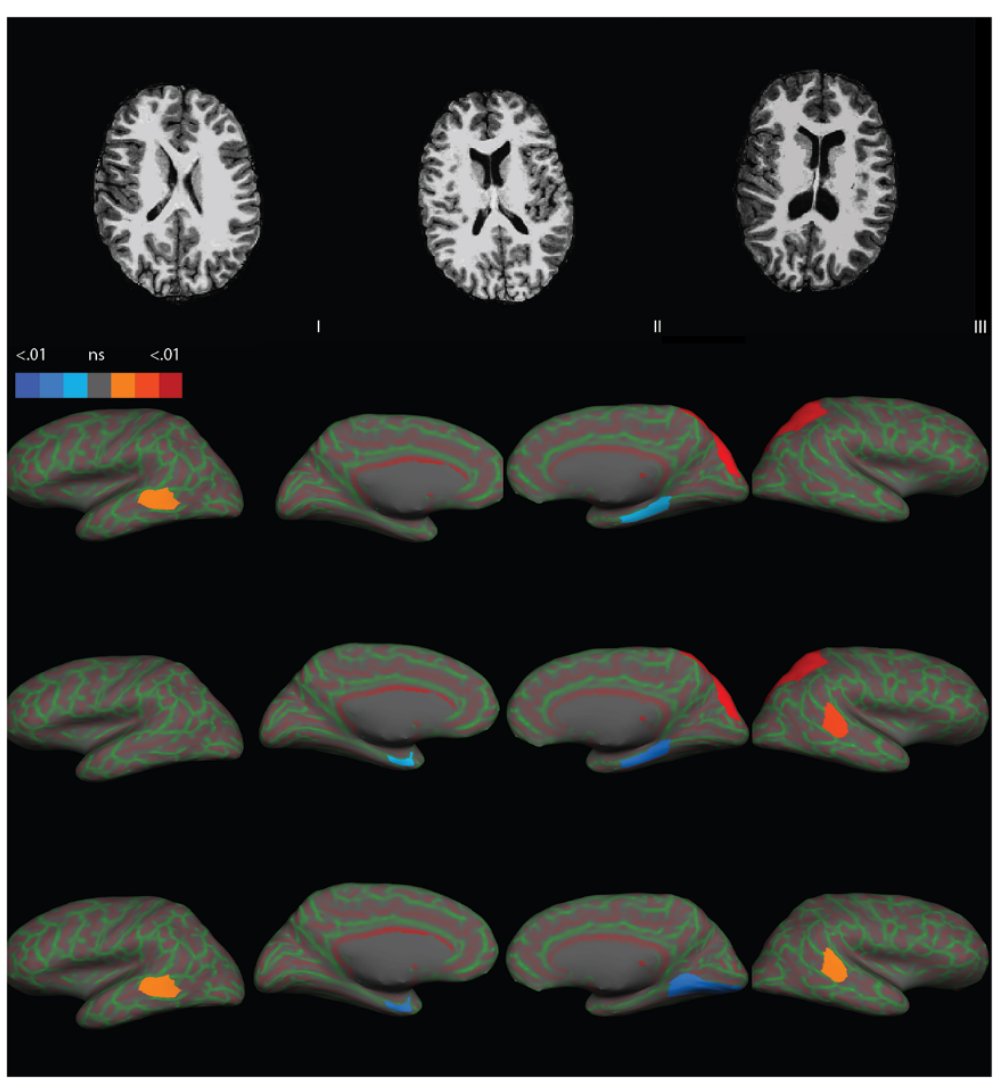

Figure 1 Ventricular enlargement and cortical focal grey matter volumes in children with PWS and healthy controls. Top row: ventricular enlargement in children with PWS. (I) Healthy control; (II) child with DEL; and (III) child with MUPD. All three presented children were of the same age and gender. Lower three rows: cortical focal measures in children with PWS and healthy controls. Cortical surface is presented inflated with curvature overlay (in green and red shades). Second row: children with DEL compared to healthy controls; third row: children with mUPD compared to healthy controls; last row: children with mUPD compared to children with DEL. All the views are in sagittal plane. Columns (from left to right): left lateral, left medial, right medial, and right lateral. DEL, deletion; mUPD, maternal uniparental disomy; PWS, Prader-Willi syndrome.

\section{Subcortical grey matter structures}

Subcortical grey matter volumes, corrected for TIV, are presented in Additional file 2: Table S2.

\section{DEL versus healthy controls}

Children with DEL had enlarged volumes of left basal ganglia $\left(P_{\text {corr }}<0.05\right)$ compared with healthy controls. No differences were found in bilateral limbic area, right basal ganglia, and bilateral thalamus.

\section{mUPD versus healthy controls}

Children with mUPD had larger left basal ganglia $(P=$ 0.026, not significant after Bonferroni correction) when compared with healthy controls. No other differences were observed.

\section{DEL versus mUPD}

No differences were found in volumes of subcortical grey volumes between children with DEL and MUPD.

\section{Discussion}

Our study is the first to investigate brain morphological differences in children with PWS using high resolution MRI techniques, and the first study to investigate differences between children with DEL and MUPD. We found that children with both DEL and MUPD had smaller brainstem volumes, and a trend towards smaller white matter volume and total cortical pial surface area compared with healthy controls, indicating early deviations in prenatal brain development in children with PWS. However, there were also differences between children with DEL and those with mUPD. Children with DEL had an overall smaller, but proportionately developed brain and normal cortical thickness, while children with mUPD had a significantly increased surface CSF and pronounced enlargement of the lateral ventricles compared to healthy controls. Further, exploratory cortical focal analyses revealed a significantly smaller white matter volume in children with mUPD in areas implicated in default mode network (DMN) and cognitive decisionmaking. Our results suggest that although both PWS 
Table 4 Focal cortical white matter volumes in children with PWS and healthy controls

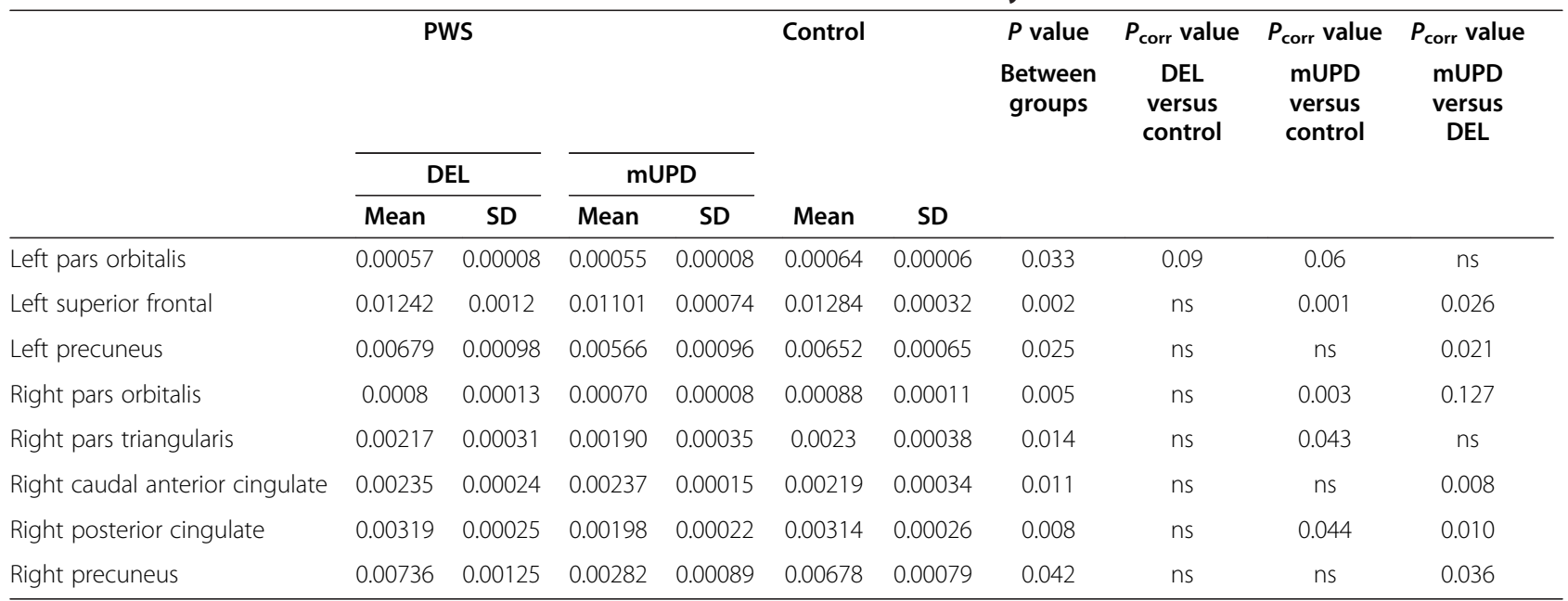

All measures presented in table are corrected for TIV. $P_{\text {corr }}$ values that did not survive the Bonferroni correction are included. $D E L$, deletion; $m U P D$, maternal uniparental disomy; ns, not significant; PWS, Prader-Willi syndrome; SD, standard deviation; TIV, total intracranial volume.

groups show global brain deficits, children with mUPD are more severely affected.

Prenatal brain development is a well-orchestrated series of events consisting of neuronal proliferation and migration, establishment of synaptic connections, myelination, and elimination of ineffective synapses (pruning) [31]. Different regions of the brain develop at different time points and pace, which in turn provides different time windows for vulnerability to perturbations, but also for effective intervention. For instance, development of brainstem is finalized during the first trimester, while development of cerebellum is initialized during the first trimester, but extends into the first year after birth [31]. Myelination is most vulnerable to insults during the late gestational period, but it continues after birth as well and extends through adolescence and into early adulthood [32]. By investigating both global and local neuroanatomical measures in children with PWS, inferences can therefore be drawn about a plausible course of neurodevelopment and the phenotype of PWS.

Both children with DEL and MUPD had smaller brainstem volume. The brainstem is responsible for several basal bodily functions, such as pain perception, respiratory regulation [33], and sleep cycle [34], all of which

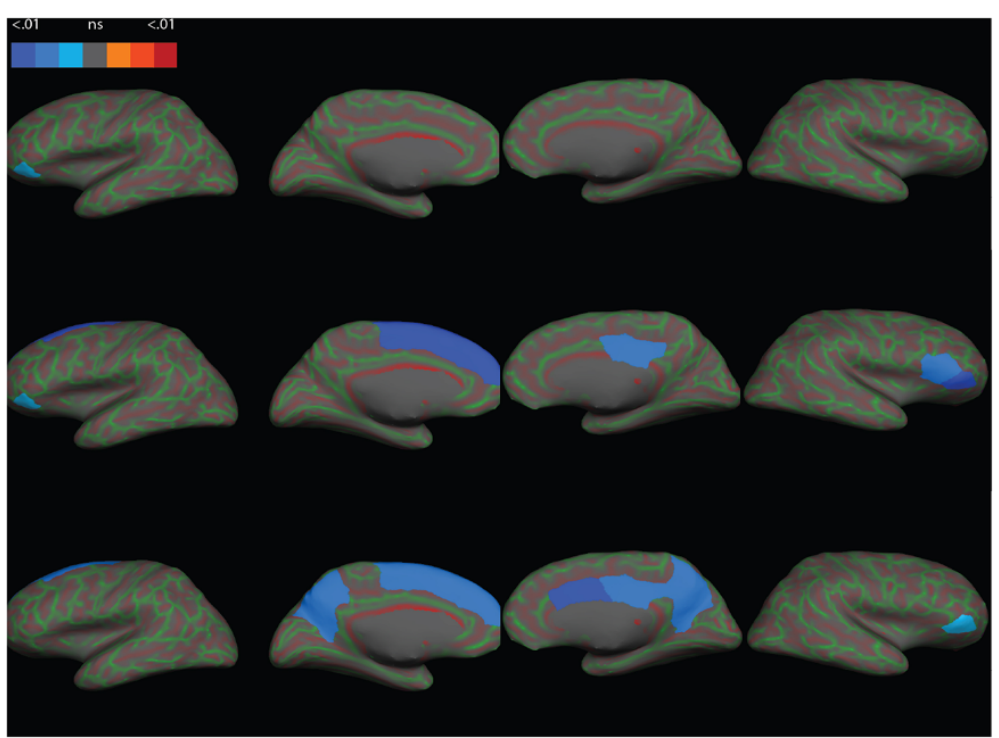

Figure 2 Focal white matter volumes in children with PWS and healthy controls. Cortical surface is presented inflated with curvature overlay (in green and red shades). Top row: children with DEL compared to healthy controls; middle row: children with mUPD compared to healthy controls; last row: children with mUPD compared to children with DEL. All the views are in sagittal plane. Columns (from left to right): left lateral, left medial, right medial, and right lateral. DEL, deletion; mUPD, maternal uniparental disomy; PWS, Prader-Willi syndrome. 
have been reported to be impaired in PWS. Central sleep apneas are common in individuals with PWS and pose an increased mortality risk at a young age [35]. A higher pain threshold has been reported in children with PWS [2], as well as disturbed sleep cycle and rapid eye movement (REM) sleep phase abnormalities [36], supporting our findings of possible brainstem dysfunction in PWS. Mice lacking necdin (in PWS locus) had smaller medullar nuclei and a disturbed respiratory rhythmogenesis [37], further suggesting that PWS region is involved in the neurodevelopment of the brainstem and the respiratory problems in patients with PWS.

Regardless of the genetic subtype, children with PWS had a trend towards smaller white matter volume, indicating reduced structural connectivity or aberrant myelination in children with PWS. Children with developmental delay showed delayed myelination [38]. The smaller white matter volume in children with PWS may therefore reflect delay in brain maturation and might underlie cognitive deficits in these children. Important to note is that several endocrine factors, namely insulinlike growth factor I (IGF-I) and thyroid hormones (T3 and T4), which are important neurochemicals involving brain and axonal growth and myelination $[39,40]$, are impaired in children with PWS, unless treated. IGF-I levels are very low in most children with PWS prior to GH treatment [17]. Low free T4 levels were reported in children with PWS as well [41]. It is therefore plausible that lower levels of thyroid hormones and IGF-I had adverse effects on brain growth and myelination.

Children with mUPD had enlarged ventricles, together with increased surface CSF volume. In adult patients with PWS, enlarged ventricles have been reported [16]. Our results suggest that ventricular enlargement occurs early in life in individuals with PWS. We do not know when during neurodevelopment the enlargement of the ventricles took place. Lateral ventricles are large at the 17th gestational week (GW), and decrease in size between 18th and 24th GW, due to multiple factors, including the increasing thickness of the brain parenchyma, cortical gyrification, and the formation of the basal ganglia [42]. In the current study, the basal ganglia were enlarged relative to the intracranial volume, which may indicate that ventricular enlargement did not occur at the cost of the basal ganglia, but more likely at the cost of the cortical volumes. Enlarged ventricles, together with increased surface CSF, probably due to the widening of the sulci, indicate disturbances in early prenatal gyrification, dendritic arborization, or postnatal neuronal atrophy in these children. Enlarged ventricles are widely reported in patients with schizophrenia, both chronic [43] and first onset medication-naive patients with schizophrenia [44], and their first-degree unaffected relatives [45]. Furthermore, enlarged lateral ventricles were also found in young children with a 22q11.2 deletion who are at very high risk of schizophrenia [46] and in adolescents with a psychotic bipolar disorder [47]. Given that children with mUPD have an elevated risk of psychotic illness, our findings suggest that ventricular enlargement may be part of a predisposition for psychotic disease.

Children with DEL showed less enlargement of the lateral ventricles and no increase in surface CSF, suggesting that brain atrophy is less pronounced in these children compared to children with mUPD. Since ventricular enlargement has been reported in adults with DEL [16], our findings suggest that children with DEL are likely to develop ventricular enlargement later in life compared to children with mUPD.

Both children with DEL and mUPD showed a trend towards smaller cortical surface area, indicating impaired prenatal brain growth [31]. The development of cortical surface area is determined by the symmetric cell division in the neural tube during the first $6 \mathrm{GW}$, and by the pronounced growth and gyrification that occurs during the third trimester [42]. Environmental insults during the first $6 \mathrm{GW}$ usually results in drastic reductions of cortical surface area [31]. It is therefore plausible that the observed mild reduction in cortical surface area may be the result of deviations in the gyrification processes during the third trimester.

Interestingly, children with DEL show a different pattern compared to children with mUPD. Smaller cortical and subcortical grey matter, brainstem, and cerebellum volumes were found, but cortical thickness was normal compared to healthy controls. The early development of cortical thickness is determined primarily through neuronal migration, which takes place between 6th and 24th GW [48]. Furthermore, from the perspective of phylogeny, cortical thickness is much more preserved compared to measures, such as brain volume and surface area [31]. Thus, normal cortical thickness may show that the genetic mechanisms involved in neuronal migration are not altered in children with DEL.

In contrast, children with mUPD showed a trend towards increased cortical thickness, which may indicate alterations in neuronal migration or impaired elimination of ineffective synapses (pruning). Increased cortical thickness has been reported in children with autism [49]. Knowing that ASD traits are very common in children with mUPD, impaired pruning might therefore affect integrative processing, complex executive, and social functions [49], and might underlie ASD symptoms in children with mUPD.

Holland et al. [50] proposed that developmental arrest might underlie the core PWS phenotype. In our study, both children with DEL and mUPD showed signs of impaired brain growth, however it was more pronounced 
in children with DEL. Furthermore, while children with DEL show signs of arrested, but not necessarily deviant, brain development, children with mUPD showed a plausible divergence in the neurodevelopmental trajectory. However, longitudinal studies are necessary to confirm the differences in neurodevelopmental trajectories between children with DEL and mUPD. An important genetic difference between individuals with DEL and mUPD is the overexpression of maternally imprinted $U B E 3 A$ gene in brains of patients with mUPD [51]. $U B E 3 A$ plays an important role in dendritic tree formation [52], and both knockout and overexpression of the $U B E 3 A$ gene results in reduced growth and branching of the dendrites [52]. UBE3A regulates synapse development and is highly expressed during a novel learning situation [53]. Overexpression of $U B E 3 A$ in mUPD and resulting failure to develop new synapses might be underlying the observed diversion, and possibly the cortical atrophy and ventricular enlargement in children with mUPD.

Exploratory cortical focal analyses revealed smaller white matter volume in the right caudal anterior and posterior cingulate cortex, left superior frontal gyrus, and bilateral precuneus in children with mUPD compared to those with DEL and to healthy controls. These areas are associated with cognitive control, moral decision-making, and emotion cognition [54], and are implicated in DMN [55,56]. The DMN is a functional brain network that is activated in the absence of cognitive tasks [56], and is thought to reflect self-oriented and social cognitive processes [57]. DMN dysfunction is associated with multiple brain disorders, such as attention deficit and hyperactivity disorder, autism, and schizophrenia [56,58-60]. Interestingly, electrophysiological correlates of decision-making was found diminished in adults with mUPD, but not in those with DEL [61], and individuals with mUPD had more autistic-like symptoms on the social interaction scale [62]. Impairment of taskswitching was found in individuals with PWS, although genetic subtypes were not reported [63]. While this should be confirmed by functional imaging studies, it is plausible that aberrant connections within these brain areas underlie social cognitive decision-making impairment in individuals with mUPD. Further, white matter volume in right pars triangularis and bilateral pars opercularis (inferior frontal gyrus (IFG)) was smaller in children with mUPD. Interestingly, lower functional connectivity in the IFG has been described in patients with schizophrenia and in individuals at ultra-high risk of developing psychosis [64], suggesting that IFG might be involved in the etiology of psychotic illness.

These results are limited by the small sample size, thus generalization to broader PWS population should be undertaken with great caution. Further, the control group consists of age- and gender-matched healthy siblings. A possible concern of recruiting siblings as the control group is that volumes of most brain structures are heritable [65]. However, as PWS occurs due to a de novo genetic event during conception, we assume that unaffected siblings are representative of a random sample of the general population. The great advantage of having siblings as the control group is that the effects of possible environmental and hereditary factors on brain development are greatly reduced, and that the observed significant differences are more likely PWS-specific.

All children with PWS were treated with GH $(1 \mathrm{mg} /$ $\mathrm{m}^{2}$ per day) at the time of the study; therefore, our findings are confounded by GH treatment. However, as it is known that GH and IGF-I increase brain growth, myelination, and has neuroprotective properties [39] we could speculate that if the GH treatment had any effect of the brain, it would have a positive effect in terms of brain normalization.

\section{Conclusions}

Our findings provide preliminary insights into the brain anatomy of children with PWS. All children with PWS showed impaired brain growth. Children with mUPD showed signs of early brain atrophy and a trend towards increased cortical thickness. In contrast, children with DEL showed signs of fundamentally arrested, although not deviant brain development. The findings in children with mUPD are reminiscent of those in schizophrenia or autism, which confirms the clinical data of increased risk of ASD and psychotic illness in individuals with mUPD. The reported brain abnormalities are likely to precede psychiatric illness as none of the children were under psychiatrist treatment at the time of the study. Our results suggest that children with mUPD have a fundamentally different brain structure and divergent developmental trajectories compared with children with DEL and healthy controls.

\section{Additional files}

Additional file 1: Table S1. Whole brain measures in children with PWS and healthy controls.

Additional file 2: Table S2. Subcortical structure measures in children with PWS and healthy controls.

\section{Abbreviations}

ASD: Autism spectrum disorders; CNS: Central nervous system;

CSF: Cerebrospinal fluid; CNVs: Copy-number variations; CC: Corpus callosum; DMN: Default mode network; DEL: Deletion; TE: Echo time; FDR: False discovery rate; GWAS: Genome-wide association study; GW: Gestational week; GM: Grey matter; GH: Growth hormone; IFG: Inferior frontal gyrus; IGFI: Insulin-like growth factor I; IQ: Intelligence quotient; IR FSPGR: Inversion recovery fast spoiled gradient recalled; TI: Inversion time; MRI: Magnetic resonance imaging; mUPD: Maternal uniparental disomy; NEX: Number of 
excitations; OCD: Obsessive-compulsive disorder; PWS: Prader-Willi syndrome; REM: Rapid eye movement; TR: Repetition time; SD: Standard deviation; SDS: Standard deviation score; STS: Superior temporal sulcus; TIV: Total intracranial volume; WISC-R: Wechsler Intelligence Scale for Children-Revised; WM: white matter.

\section{Competing interests}

The authors declare that they have no competing interests.

\section{Authors' contributions}

$\mathrm{AL}, \mathrm{ACHK}$ and $\mathrm{AVDL}$ designed the study. AL collected and analyzed the data and wrote the manuscript. TW contributed to the analysis and interpretation of the data as well as writing of the manuscript. TW and MS helped with technical aspects of the MRI acquisition, data processing and analysis. ACHK is a principal investigator and supervisor of the project, and contributed to data analysis and writing of the manuscript. All authors read and approved the final manuscript.

\section{Acknowledgements}

We would like to thank parents and children for their participation. We also thank Afzal Bechan and Marielle van Eekelen for their assistance with the MRI acquisition, and Zyrhea Troeman for conducting the biannual IQ tests. This study was financially supported by the Foundation for Prader-Willi Research, Los Angeles, CA, USA, and Dutch Growth Research Foundation, Rotterdam, The Netherlands.

\section{Author details}

${ }^{1}$ Dutch Growth Research Foundation, Postbus 23068, Rotterdam 3001, KB, The Netherlands. ${ }^{2}$ Department of Pediatrics, Erasmus Medical Center Rotterdam - Sophia Children's Hospital Rotterdam, Postbus 2060, Rotterdam 3000, CB, The Netherlands. ${ }^{3}$ Department of Child and Adolescent Psychiatry, Erasmus Medical Center Rotterdam - Sophia Children's Hospital, Postbus 2060, Rotterdam 3000, CB, The Netherlands. ${ }^{4}$ Department of Radiology, Erasmus Medical Center Rotterdam, Postbus 2040, Rotterdam 3000, CA, The Netherlands.

Received: 17 June 2013 Accepted: 2 October 2013

Published: 22 October 2013

\section{References}

1. Soni S, Whittington J, Holland AJ, Webb T, Maina EN, Boer H, Clarke D: The phenomenology and diagnosis of psychiatric illness in people with Prader-Willi syndrome. Psychol Med 2008, 38:1505-1514.

2. Cassidy SB, Forsythe M, Heeger S, Nicholls RD, Schork N, Benn P, Schwartz S: Comparison of phenotype between patients with Prader-Willi syndrome due to deletion 15q and uniparental disomy 15. Am J Med Genet 1997, 68:433-440

3. Ledbetter DH, Riccardi VM, Airhart SD, Strobel RJ, Keenan BS, Crawford JD: Deletions of chromosome 15 as a cause of the prader-willi syndrome. N Engl J Med 1981, 304:325-329.

4. Nicholls RD, Knoll JHM, Butler MG, Karam S, Lalande M: Genetic imprinting suggested by maternal heterodisomy in non-deletion Prader-Willi syndrome. Nature 1989, 342:281-285.

5. Buiting K, Saitoh S, Gross S, Dittrich B, Schwartz S, Nicholls RD, Horsthemke $B$ : Inherited microdeletions in the Angelman and Prader-Willi syndromes define an imprinting centre on human chromosome 15. Nat Genet 1995, 9:395-400.

6. Perala J, Suvisaari J, Saarni SI, Kuoppasalmi K, Isometsa E, Pirkola S, Partonen T, Tuulio-Henriksson A, Hintikka J, Kieseppa T: Lifetime prevalence of psychotic and bipolar I disorders in a general population. Arch Gen Psychiatry 2007, 64:19.

7. Soni S, Whittington J, Holland AJ, Webb T, Maina E, Boer H, Clarke D: The course and outcome of psychiatric illness in people with Prader-Willi syndrome: implications for management and treatment. J Intellect Disabil Res 2007, 51:32-42.

8. Stefansson H, Rujescu D, Cichon S, Pietiläinen OP, Ingason A, Steinberg S, Fossdal R, Sigurdsson E, Sigmundsson T, Buizer-Voskamp JE, Hansen $T$, Jakobsen KD, Muglia P, Francks C, Matthews PM, Gylfason A, Halldorsson BV, Gudbjartsson D, Thorgeirsson TE, Sigurdsson A, Jonasdottir A, Jonasdottir A, Bjornsson A, Mattiasdottir S, Blondal T, Haraldsson M, Magnusdottir BB, Giegling I, Möller HJ, Hartmann A:
Large recurrent microdeletions associated with schizophrenia. Nature 2008, 455:232-236

9. Veltman MWM, Craig EE, Bolton PF: Autism spectrum disorders in Prader-Willi and Angelman syndromes: a systematic review. Psychiatr Genet 2005, 15:243.

10. Baird G, Simonoff E, Pickles A, Chandler S, Loucas T, Meldrum D, Charman T: Prevalence of disorders of the autism spectrum in a population cohort of children in South Thames: the Special Needs and Autism Project (SNAP). Lancet 2006, 368:210-215.

11. Moreno-De-Luca D, Sanders SJ, Willsey AJ, Mulle JG, Lowe JK, Geschwind DH, State MW, Martin CL, Ledbetter DH: Using large clinical data sets to infer pathogenicity for rare copy number variants in autism cohorts. Mol Psychiatry 2013, 18:1090-1095.

12. Sullivan PF, Magnusson C, Reichenberg A, Boman M, Dalman C, Davidson M, Fruchter E, Hultman CM, Lundberg M, Långström N, Weiser M, Svensson AC, Lichtenstein P: Family history of schizophrenia and bipolar disorder as risk factors for autism. Arch Gen Psychiatry 2012, 69:1099-1103.

13. Carroll LS, Owen MJ: Genetic overlap between autism, schizophrenia and bipolar disorder. Genome Med 2009, 1:102.

14. Ogura K, Fujii T, Abe N, Hosokai Y, Shinohara M, Takahashi S, Mori E: Small gray matter volume in orbitofrontal cortex in prader-willi syndrome: a voxel-based MRI study. Hum Brain Mapp 2011, 32:1059-1066.

15. Honea RA, Holsen LM, Lepping RJ, Perea R, Butler MG, Brooks WM, Savage CR: The neuroanatomy of genetic subtype differences in Prader-Willi syndrome. Am J Med Genet B Neuropsychiatr Genet 2012, 159:243-253.

16. Miller JL, Couch JA, Schmalfuss I, He G, Liu Y, Driscoll DJ: Intracranial abnormalities detected by three-dimensional magnetic resonance imaging in Prader-Willi syndrome. Am J Med Genet A 2007, 143:476-483.

17. Festen DAM, Wevers $M$, Lindgren AC, Böhm B, Otten BJ, Wit JM Duivenvoorden HJ, Hokken Koelega AC: Mental and motor development before and during growth hormone treatment in infants and toddlers with Prader-Willi syndrome. Clin Endocrinol (Oxf) 2008, 68:919-925.

18. Van-Haasen P, De-Bruyn E, Pij Y, Poortinga Y, Lutje-Spelberg H, Vander Steene G, Coetsier P, Spoelders-Claes R, Stinissen J: Wechsler intelligence scale for children-revised, Dutch version. Lisse, The Netherlands: Swets and Zetlinger BV; 1986

19. Siemensma EP, Tummers-de Lind van Wijngaarden RF, Festen DA, Troeman ZC, Van Alfen-van der Velden AA, Otten BJ, Rotteveel J, Odink RJ, Bindels-de Heus GC, Van-Leeuwen M, Haring DA, Oostdijk W, Bocca G, Mieke Houdijk EC, Van-Trotsenburg AS, Hoorweg-Nijman JJ, Van-Wieringen H, Vreuls RC, Jira PE, Schroor EJ, Van-Pinxteren-Nagler E, Willem Pilon J, Lunshof LB, Hokken-Koelega AC: Beneficial effects of growth hormone treatment on cognition in children with Prader-Willi syndrome: a randomized controlled trial and longitudinal study. J Clin Endocrinol Metab 2012, 97:2307-2314.

20. White T, Marroun H, Nijs I, Schmidt M, Lugt A, Wielopolki P, Jaddoe W, Hofman A, Krestin G, Tiemeier H, Verhulst F: Pediatric population-based neuroimaging and the generation $\mathrm{R}$ study: the intersection of developmental neuroscience and epidemiology. Eur J Epidemiol 2013, 28:99-111.

21. Dale AM, Fischl B, Sereno Ml: Cortical surface-based analysis: segmentation and surface reconstruction. Neuroimage 1999, 9:179-194

22. Segonne F, Dale A, Busa E, Glessner M, Salat D, Hahn H, Fischl B: A hybrid approach to the skull stripping problem in MRI. Neuroimage 2004, 22:1060-1075.

23. Fischl B, Salat DH, van der-Kouwe AJW, Makris N, Segonne F, Quinn BT, Dale AM: Sequence-independent segmentation of magnetic resonance images. Neuroimage 2004, 23:S69-S84.

24. Fischl B, Salat DH, Busa E, Albert M, Dieterich M, Haselgrove $C$, van derKouwe A, Killiany R, Kennedy D, Klaveness S: Whole brain segmentation: automated labeling of neuroanatomical structures in the human brain. Neuron 2002, 33:341-355.

25. Sled JG, Zijdenbos AP, Evans AC: A nonparametric method for automatic correction of intensity nonuniformity in MRI data. IEEE Trans Med Imaging 1998, 17:87-97.

26. Fischl B, Liu A, Dale AM: Automated manifold surgery: constructing geometrically accurate and topologically correct models of the human cerebral cortex. IEEE Trans Med Imaging 2001, 20:70-80. 
27. Desikan RS, Ségonne F, Fischl B, Quinn BT, Dickerson BC, Blacker D, Buckner RL, Dale AM, Maguire RP, Hyman BT: An automated labeling system for subdividing the human cerebral cortex on MRI scans into gyral based regions of interest. Neuroimage 2006, 31:968-980.

28. Fischl B, Dale AM: Measuring the thickness of the human cerebral cortex from magnetic resonance images. Proc Natl Acad Sci 2000, 97:11050-11055.

29. Rosas H, Liu A, Hersch S, Glessner M, Ferrante R, Salat D, van Der-Kouwe A, Jenkins B, Dale A, Fischl B: Regional and progressive thinning of the cortical ribbon in Huntington's disease. Neurology 2002, 58:695-701.

30. Han X, Jovicich J, Salat D, van der-Kouwe A, Quinn B, Czanner S, Busa E, Pacheco J, Albert M, Killiany R: Reliability of MRI-derived measurements of human cerebral cortical thickness: the effects of field strength, scanner upgrade and manufacturer. Neuroimage 2006, 32:180-194.

31. Rice $D$, Barone $S \mathrm{Jr}$ : Critical periods of vulnerability for the developing nervous system: evidence from humans and animal models. Environ Health Perspect 2000, 108:511.

32. Yakovlev $P$, Lecours A: The myelogenetic cycles of regional maturation of the brain. In Regional development of the brain in early life. Edited by Minkowski A. Oxford: Blackwell; 1967:3-70.

33. Feldman $\lrcorner$, Ellenberger $\mathrm{HH}$ : Central coordination of respiratory and cardiovascular control in mammals. Annu Rev Physiol 1988, 50:593-606.

34. Snyderman NL, Johnson JT, Muller M, Thearle PB: Brainstem evoked potentials in adult sleep apnea. Ann Otol Rhinol Laryngol 1982, 91:597-598.

35. Festen DAM, De-Weerd AW, van den-Bossche RAS, Joosten $\mathrm{K}$, Hoeve $H$, Hokken-Koelega AC: Sleep-related breathing disorders in prepubertal children with Prader-Willi syndrome and effects of growth hormone treatment. J Clin Endocrinol Metab 2006, 91:4911-4915.

36. Hertz G, Cataletto M, Feinsilver SH, Angulo M: Sleep and breathing patterns in patients with Prader Willi syndrome (PWS): effects of age and gender. Sleep 1993, 16:366.

37. Pagliardini S, Ren J, Wevrick R, Greer JJ: Developmental abnormalities of neuronal structure and function in prenatal mice lacking the prader-willi syndrome gene necdin. Am J Pathol 2005, 167:175-191.

38. Pujol J, López-Sala A, Sebastián-Gallés N, Deus J, Cardoner N, Soriano-Mas C, Moreno A, Sans A: Delayed myelination in children with developmental delay detected by volumetric MRI. Neuroimage 2004, 22:897-903.

39. Carson MJ, Behringer RR, Brinster RL, McMorris FA: Insulin-like growth factor I increases brain growth and central nervous system myelination in transgenic mice. Neuron 1993, 10:729-740.

40. Bernal J, Nunez J: Thyroid hormones and brain development. Eur J Endocrinol 1995, 133:390-398.

41. Festen DAM, Visser TJ, Otten BJ, Wit JM, Duivenvoorden HJ, Hokken-Koelega AC: Thyroid hormone levels in children with Prader-Willi syndrome before and during growth hormone treatment. Clin Endocrinol (Oxf) 2007, 67:449-456.

42. Prayer D, Kasprian G, Krampl E, Ulm B, Witzani L, Prayer L, Brugger PC: MRI of normal fetal brain development. Eur J Radiol 2006, 57:199-216.

43. Kempton MJ, Stahl D, Williams SCR, DeLisi LE: Progressive lateral ventricular enlargement in schizophrenia: a meta-analysis of longitudinal MRI studies. Schizophr Res 2010, 120:54-62.

44. Steen RG, Mull C, McClure R, Hamer RM, Lieberman JA: Brain volume in first-episode schizophrenia: systematic review and meta-analysis of magnetic resonance imaging studies. Br J Psychiatry 2006, 188:510-518.

45. McDonald C, Grech A, Toulopoulou T, Schulze K, Chapple B, Sham P, Walshe M, Sharma T, Sigmundsson T, Chitnis X, Murray RM: Brain volumes in familial and non-familial schizophrenic probands and their unaffected relatives. Am J Med Genet 2002, 114:616-625.

46. Campbell LE, Daly E, Toal F, Stevens A, Azuma R, Catani M, Ng V, Van-Amelsvoort T, Chitnis X, Cutter W, Murphy DG, Murphy KC: Brain and behaviour in children with 22q11.2 deletion syndrome: a volumetric and voxel-based morphometry MRI study. Brain 2006, 129:1218-1228.

47. Edmiston EE, Wang F, Kalmar JH, Womer FY, Chepenik LG, Pittman B, Gueorguieva R, Hur E, Spencer L, Staib LH, Constable RT, Fulbright RK, Papademetris X, Blumberg HP: Lateral ventricle volume and psychotic features in adolescents and adults with bipolar disorder. Psychiatry Res 2011, 194:400-402.

48. Rakic P: Principles of neural cell migration. Experientia 1990, 46:882-891

49. Hill EL, Frith U: Understanding autism: insights from mind and brain. Philos Trans R Soc Lond B Biol Sci 2003, 358:281-289.
50. Holland AJ, Whittington JE, Butler J, Webb T, Boer H, Clarke D: Behavioural phenotypes associated with specific genetic disorders: evidence from a population-based study of people with Prader-Willi syndrome. Psychol Med 2003, 33:141-153.

51. Hogart A, Leung KN, Wang NJ, Wu DJ, Driscoll J, Vallero RO, Schanen NC, La-Salle JM: Chromosome 15q11-q13 duplication syndrome brain reveals epigenetic alterations in gene expression not predicted from copy number. J Med Genet 2009, 46:86-93.

52. Lu Y, Wang F, Li Y, Ferris J, Lee JA, Gao FB: The Drosophila homologue of the Angelman syndrome ubiquitin ligase regulates the formation of terminal dendritic branches. Hum Mol Genet 2009, 18:454-462.

53. Greer PL, Hanayama R, Bloodgood BL, Mardinly AR, Lipton DM, Flavell SW, Kim TK, Griffith EC, Waldon Z, Maehr R, Ploegh HL, Chowdhury S, Worley PF, Steen J, Greenberg ME: The Angelman Syndrome protein Ube3A regulates synapse development by ubiquitinating arc. Cell 2010, 140:704-716.

54. Mulert C, Pogarell O, Juckel G, Rujescu D, Giegling I, Rupp D, Mavrogiorgou P, Bussfeld P, Gallinat J, Möller HJ, Hegerl U: The neural basis of the P300 potential. Eur Arch Psychiatry Clin Neurosci 2004, 254:190-198.

55. Fransson P, Marrelec G: The precuneus/posterior cingulate cortex plays a pivotal role in the default mode network: evidence from a partial correlation network analysis. Neuroimage 2008, 42:1178-1184.

56. Greicius M: Resting-state functional connectivity in neuropsychiatric disorders. Curr Opin Neurol 2008, 21:424-430.

57. Spreng RN, Grady CL: Patterns of brain activity supporting autobiographical memory, prospection, and theory of mind, and their relationship to the default mode network. J Cogn Neurosci 2009, 22:1112-1123

58. Uddin LQ, Kelly A, Biswal BB, Margulies DS, Shehzad Z, Shaw D, Ghaffari M, Rotrosen J, Adler LA, Castellanos FX: Network homogeneity reveals decreased integrity of default-mode network in ADHD. J Neurosci Methods 2008, 169:249-254.

59. Assaf M, Jagannathan K, Calhoun VD, Miller L, Stevens MC, Sahl R, O'Boyle JG, Schultz RT, Pearlson GD: Abnormal functional connectivity of default mode sub-networks in autism spectrum disorder patients. Neuroimage 2010, 53:247-256.

60. Whitfield-Gabrieli S, Thermenos HW, Milanovic S, Tsuang MT, Faraone SV, McCarley RW, Shenton ME, Green Al, Nieto-Castanon A, LaViolette P, Wojcik J, Gabrieli JD, Seidman LJ: Hyperactivity and hyperconnectivity of the default network in schizophrenia and in first-degree relatives of persons with schizophrenia. Proc Natl Acad Sci U S A 2009, 106:1279-1284.

61. Stauder JE, Boer H, Gerits RH, Tummers A, Whittington J, Curfs LM: Differences in behavioural phenotype between parental deletion and maternal uniparental disomy in Prader-Willi syndrome: an ERP study. Clin Neurophysiol 2005, 116:1464-1470.

62. Milner KM, Craig EE, Thompson RJ, Veltman MW, Thomas NS, Roberts S, Bellamy M, Curran SR, Sporikou CM, Bolton PF: Prader-Willi syndrome: intellectual abilities and behavioural features by genetic subtype. J Child Psychol Psychiatry 2005, 46:1089-1096.

63. Woodcock KA, Oliver C, Humphreys GW: Task-switching deficits and repetitive behaviour in genetic neurodevelopmental disorders: data from children with Prader-Willi syndrome chromosome 15 q11-q13 deletion and boys with Fragile X syndrome. Cogn Neuropsychol 2009, 26:172-194.

64. Jung WH, Jang JH, Shin NY, Kim SN, Choi C-H, An SK, Kwon JS: Regional brain atrophy and functional disconnection in Broca's area in individuals at ultra-high risk for psychosis and schizophrenia. PLoS One 2012, 7:e51975.

65. Wallace GL, Eric Schmitt J, Lenroot R, Viding E, Ordaz S, Rosenthal MA, Molloy EA, Clasen LS, Kendler KS, Neale MC, Giedd JN: A pediatric twin study of brain morphometry. J Child Psychol Psychiatry 2006, 47:987-993.

\section{doi:10.1186/1866-1955-5-31}

Cite this article as: Lukoshe et al:: Divergent structural brain

abnormalities between different genetic subtypes of children with Prader-Willi syndrome. Journal of Neurodevelopmental Disorders 2013 5:31. 